C2016, Elsevier. Licensed under the Creative Commons Attribution-NonCommercialNoDerivatives 4.0 International http://creativecommons.org/about/downloads 


\section{Personality, motives and metacognitions as predictors of problematic Facebook use in university students}

\section{Regular Article}

Claudia Marino, ${ }^{\mathrm{a}, \mathrm{b}, *}$, Alessio Vieno ${ }^{\mathrm{a}}$, Antony C. Moss ${ }^{\mathrm{b}}$, Gabriele Caselli ${ }^{\mathrm{b}, \mathrm{c}, \mathrm{d}}$, Ana V. Nikčević ${ }^{\mathrm{e}}$, and Marcantonio M. Spada ${ }^{\mathrm{b}}$

${ }^{a}$ Dipartimento di Psicologia dello Sviluppo e della Socializzazione, Università degli Studi di Padova, Padova, Italy

${ }^{\mathrm{b}}$ Division of Psychology, School of Applied Sciences, London South Bank University, London, UK

${ }^{\mathrm{c}}$ Studi Cognitivi, Milano, Italy

${ }^{\mathrm{d}}$ Sigmund Freud University, Milano, Italy

${ }^{\mathrm{e}}$ Department of Psychology, Kingston University, Kingston-upon-Thames, UK

* Correspondence should be addressed to: Claudia Marino, Dipartimento di Psicologia dello Sviluppo e della Socializzazione, Università degli Studi di Padova, via Venezia 8, Padova, Italy, e-mail claudia.marino@studenti.unipd.it. 


\begin{abstract}
Facebook has become hugely popular among young people and adults all over the world, creating a new social phenomenon that has affected the communication patterns used by people to interact with each other. Although most people use Facebook wisely, a minority of users can show negative patterns of Facebook use, with negative consequences on personal psycho-social well-being, especially among young adults. The present study aims to test a model designed to assess the unique contribution of personality traits, motives for using Facebook and metacognitions on Problematic Facebook Use (PFU) among young adults. A total of 815 Italian university students participated in the study. Path analysis revealed that three of the four motives to use Facebook, and that two of the five metacognitions, predicted PFU. Moreover, only one personality trait (extraversion) appeared to be directly linked to PFU, while emotional stability indirectly influenced PFU via motives (coping and conformity) and metacognitions (negative beliefs about worry and cognitive confidence). In conclusion, motives and metacognitions predict PFU among young adults, and they should be taken into account to develop preventive measures and clinical interventions.
\end{abstract}

Keywords: Metacognitions; personality; problematic Facebook use; young adults. 


\section{Introduction}

Over the last decade Facebook has become hugely popular among young people and adults all over the world, creating a new social phenomenon that has affected the communication patterns used by people to interact with each other (Lee, Cheung, \& Thadani, 2012). Researchers have pointed out the positive effects of Facebook use on well-being (Ellison, Steinfield, \& Lampe, 2007; Kuss \& Griffiths, 2011). For example, it has been recognized as a positive tool for anxious people to increase their perceived social support (Indian \& Grieve, 2014) and for adolescents to improve their civic engagement skills (Lenzi, Vieno, Altoè, Scacchi, Perkins, Zukauskiene, \& Santinello, 2015). However, other studies have highlighted a number of negative correlates of extensive Facebook use, such as detrimental impact on academic performance for university students (Kirschner \& Karpinski, 2010) and problems in romantic relationships through excessive jealousy and interpersonal electronic surveillance (Muise, Christofides, \& Desmarais, 2009).

Although most people use Facebook wisely, a minority of users displays negative patterns of Facebook use (Kuss \& Griffiths, 2011). Problematic Facebook Use (henceforth PFU) is defined as "the use of Facebook that creates psychological, social, school/or work difficulties in person's life" (Lee et al., 2012, p.1769). PFU has been identified as potential marker of psychopathological distress, including depression, social anxiety, negative parental and peer attachment (Moreau, Laconi, Delfour, \& Chabrol, 2015). Moreover, Kuss and colleagues (2011) argued that it appears to fall in the "cyber-relationship" category proposed by Young (1999) to discriminate different types of Internet Addiction. Despite the fact that Internet Addiction and PFU have not yet been classified as recognized disorders, many studies support the idea that Internet and Facebook use could take the form of behavioural addictions, especially in younger populations (Kuss \& Griffiths, 2011).

For the purposes of the current study, following Lee and colleagues' (2012) suggestion, we adopted Caplan's (2010) Generalized Problematic Internet Use approach in the Facebook context to operationalize PFU. The model appears a good starting point for investigating PFU because it highlights negative consequences, cognitive and emotional regulation, and social interactions as 
important elements in the definition of this potentially addictive behaviour (Ryan, Chester, Reece, \& Xenos, 2014).

Recent reviews focused on Facebook (Kuss \& Griffiths, 2011; Ryan et al., 2014) have revealed that there is an increasing number of scientific outputs highlighting possible predictors of PFU (e.g., personality traits, levels of social anxiety, motivations for Facebook use). However, to date, there is still a lack of theory-driven empirical research on psychological mechanisms that may lead to PFU (Lee et al., 2012). The current study is the first to test the unique role of personality traits, motives for addictive behaviours and metacognitions in explaining PFU among young adults.

\subsection{Personality traits and Facebook Use}

A classic means of categorizing personality is the widely-used Five-Factor Model (Caprara et al., 1993; Caprara et al., 1994). Briefly, this model identifies five dimensions in human personality: Extraversion (reflecting expansiveness and energy), Agreeableness (reflecting concern and politeness), Conscientiousness (reflecting orderliness and precision), Emotional Stability (reflecting the capacity to cope with anxiety and emotionality), and Openness (reflecting openness to novelty and interest toward different people and cultures).

In previous studies that have applied this model to Facebook use, people low in extraversion and in emotional stability were found to be more likely to engage in Facebook use (AmichaiHamburger, Wainapel, \& Fox, 2002). Moreover, people high in agreeableness have been found to use Facebook to enhance their interpersonal successes by posting and connecting with others (Marshall, Lefringhausen, \& Ferenczi, 2015), while people high in openness to experience have been observed to frequently find and share information (Hughes, Rowe, Batey, \& Lee, 2012). Finally, those high in conscientiousness may strive for an ever-increasing number of friends or may overuse the organizing tools provided by Facebook (Amichai-Hamburger \& Vinitzky, 2010).

\subsection{Motives Underlying PFU}


In the last eight years, many studies have outlined the motives underlying Facebook use, trying to understand the specific needs people expect to satisfy using Facebook (Sheldon, 2008; for a review, see Ryan et al., 2014). Some of these works, using the Use and Gratification paradigm (Papacharissi \& Mendelson, 2011), found the existence of instrumental motivations, directly linked to the tools Facebook provides, such as relationship maintenance through sending messages and posting on the friends' wall, entertainment through reading other people's profiles, passing time (Sheldon, 2008), developing new friendship relationships, and escapism (Floros \& Siomos, 2013). Kuss and Griffiths (2011) argued that the main motivation to use Facebook might be that of establishing and/or maintaining both online and offline relationships.

As recently pointed out by Bischof-Kastner and colleagues (Bischof-Kastner, Kuntsche, \& Wolstein, 2014), despite the importance of these motivations in predicting Internet and Facebook use, many studies have failed to concomitantly consider the important role of affectivity in understanding problematic Internet use (henceforth PIU), and PFU in particular. One promising approach which considers affectivity, and allows a classification of the different motives behind Internet use, was proposed by Bischof-Kastnerand and colleagues (2014) on the basis of the traditional motivational model for addictions (Cox \& Klinger, 1988). According to the motivational model of addictive behaviours people behave in certain ways to achieve expected or desired effects. Four motives result from crossing two orthogonal dimensions: (1) positive or negative valence (i.e. increasing or decreasing positive or negative feelings); and (2) internal or external source (in respect to one's own sensations or to significant others, respectively). The resulting four motives are: (i) enhancement (positive valence and internal source; that is, to expect to enhance positive affect by using Facebook); (ii) coping (negative valence and internal source; that is, to expect to diminishing bad feelings by using Facebook); (iii) conformity (negative valence and external source; to use Facebook because of the peer pressure to use it); and (iv) social (positive valence and external source; that is, to expect to improve contact and relationships with friends). Based on this model, in this study, the Internet Motives Questionnaire (Bischof-Kastner et al., 2014) was adapted to 
specifically measure Facebook motives after the successful adaptation to several behaviours beyond alcohol use (Mazzardis, Vieno, Kuntsche, \& Santinello, 2010), including gambling (Canale, Vieno, Griffiths, Rubaltelli, \& Santinello, 2015), sexual risk-taking behaviour (Cooper, Shapiro, \& Powers, 1998) and listening to music (Kuntsche, Le Mével, \& Berson, 2014).

\subsection{Metacognitions and PFU}

Metacognitions have been defined as "the information individuals hold about their own cognition and internal states, and about coping strategies that impact both" (Wells, 2000). Cartwright-Hatton and Wells (1997; Wells \& Cartwright-Hatton, 2004) assessed metacognitions through five factors: (i) positive beliefs about worry (measuring beliefs that perseverative thinking is useful); (ii) negative beliefs about thoughts (measuring beliefs that perseverative thinking is dangerous); (iii) cognitive confidence (in one's own attention and memory); (iv) beliefs about the need to control thoughts; and (v) cognitive self-consciousness (assessing the tendency to self-focus attention and to monitor thoughts). According to the metacognitive theoretical tenet (Wells, 2000), metacognitions play an important role in leading individuals to develop coping strategies including worry, rumination, avoidance and thoughts suppression, treat monitoring and maladaptive behaviours. Evidence suggests that metacognitions are implicated in all psychological problems (for a review, see Wells, 2013).

Spada and colleagues (Spada, Langston, Nikčević, \& Moneta, 2008) have identified the role of metacognitions in PIU. They found that all five dimensions of metacognitions, as measured by the Metacognitions Questionnaire-30 (Wells \& Cartwright-Hatton, 2004), were correlated with PIU. They also tested a mediation model in which negative emotions predicted metacognitions which in turn predicted PIU, observing that the relationship between negative emotions and PIU was entirely mediated by metacognitions. They thus postulated that metacognitions predict PIU because they lead to an escalation in negative emotions (through the activation of maladaptive coping strategies such as rumination and worry), which in turn increases the likelihood of utilizing the Internet as a means of cognitive-affective self-regulation. In other words, using the Internet (for example by 
seeking information to reduce preoccupations and psychological discomfort) becomes a strategy to control emotional states (Spada et al., 2008). It is plausible to assume that metacognitions may play a similar role in PFU as the latter has been found to be employed as means for regulating emotions and cognitive preoccupations (Caplan, 2010).

\subsection{Aim of the Current Study}

The present study aims to test a model designed to assess the unique contribution of personality traits, motives for using Facebook and metacognitions on PFU among young adults. The conceptual model is presented in Figure 1 and the following hypotheses directly derive from the literature and sustain the model structure. First, as reviewed above, a number of personality traits have been found to be associated with different patterns of Facebook use and with PFU (e.g., Amichai-Hamburger et al., 2002; Kuss \& Griffiths, 2011; Marshall et al., 2015). Young adults high in personality traits like openness, conscientiousness and agreeableness are expected to report higher levels of PFU for several reasons, such as enhancing their interpersonal successes by connecting with others or finding and sharing information. Conversely, high emotional stability and extraversion should be associated with lower PFU. Therefore, we tested whether personality traits are directly linked to PFU:

Hypothesis 1: PFU will be positively associated with openness, conscientiousness and agreeableness and negatively associated with emotional stability and extraversion.

Second, a number of scholars have tried to understand why people use social networking sites (Joinson, 2008; Papacharissi \& Mendelsohn, 2011). However, no attempt has been made to investigate the possible link between PFU and motives for doing so, which have often been found to be significant predictors of other addictive behaviours (Bischof-Kastner et al., 2014). Specifically, enhancement and coping motives have been found to predict PIU, whereas conformity and social motives appear to be linked only to the frequency of Internet use (Bischof-Kastner et al., 2014). Therefore, we tested whether such theory-driven motives are directly linked to PFU: 
Hypothesis 2: PFU will be positively associated with coping, conformity, enhancement, and social motives.

Third, assuming that PFU is a form of deficient self-regulatory strategy (Caplan, 2010), metacognitions could influence such maladaptive behaviour, by predisposing people to develop maladaptive coping strategies to thoughts and internal events, which may lead to Facebook use as a means of self-regulation. Therefore, we tested whether metacognitions are directly linked to PFU:

Hypothesis 3: PFU will be positively associated with positive beliefs about worry, negative beliefs about thoughts, cognitive confidence, need to control thoughts, and cognitive selfconsciousness.

Fourth, based on theories of personality (Caprara et al., 1993), it is likely that most associations of personality traits with PFU are indirect and mediated, at least partially, by individual motives and metacognitions. Caprara and Cervone (2000) have indeed defined personality traits as a set of internal systems that arise and act during the life span facilitating personal adaptation. This set of self-regulatory systems guide motivational and cognitive processes. Literature on different risky behaviours suggests that personality traits indirectly influence risky behaviours by activating certain needs and thoughts, which, in turn, may be encountered by engaging in the target behaviour (e.g., Cooper, Agocha, \& Sheldon, 2000). Specifically, personality traits represent salient ways in which individuals differ in their motivational styles (McCrae \& John, 1992) and metacognition appears to be influenced by different personality traits (Chiaburu, Cho, \& Gardner, 2015). Therefore, it is important to include motives and metacognitions when investigating the link between personality traits and health or behavioural outcomes. Moreover, in the motivational model (Cox \& Klinger, 1988), motives to engage in a behaviour result from a variety of expectancies linked to personality, memories, and perceptions. Such individual characteristics may influence also the information individuals hold about their cognition and internal states (Spada et al., 2008). Therefore, we tested the potential mediation role of motives and metacognitions in the relationship between personality and PFU. 
Hypothesis 4: The relationship between personality and PFU will be mediated by motives to use Facebook and by metacognitions.

While a few studies have analyzed some of the current associations, to date, no attempt has been made to investigate the possible links between personality traits, motives, metacognitions and PFU altogether in a single study. The present study sought to test a single model, in which the contribution of each component to PFU is considered above and beyond that of the other components.

\section{Method}

\subsection{Participants}

822 respondents answered an on-line questionnaire during the academic year 2015/2016. Participants were Italian university students aged between 18 and 35 years (mean age $=21.17, S D=$ $2.15 ; 77.1 \%$ females) and were from different faculties (31\% liberal arts; $36 \%$ psychology; $12 \%$ science; $22 \%$ other faculties). Seven participants declared not to have a Facebook account and were excluded from analyses. Therefore, the analyses were run on a final sample of 815 students.

\subsection{Measurement of Key Variables}

For each measure a confirmatory factor analysis was performed with DWLS estimator (Jöreskog \& Sörbom, 1993) to test for the construct validity of each measure. To evaluate the fit of a model, the following criteria are commonly considered: Comparative-Fit Index (CFI; adequate fit: >.90; good fit: > 0.95); Non-Normed Fit Index (NNFI; adequate fit: >.90; good fit: > 0.95); and Root Mean Square Error of Approximation (RMSEA; adequate fit: <.08; good fit: < 0.05) (e.g., Browne \& Cudeck, 1993; Hu \& Bentler, 1999).

Problematic Facebook Use. PFU was measured with fifteen items adapted from the scale developed and validated by Caplan (2010) for the measurement of Generalized Problematic Internet Use. Items were translated from English to Italian and back-translated in English by a bilingual psychologist. Simply replacing the word "Internet" with the word "Facebook" made adaptation from Internet to Facebook context. Participants were asked to rate the extent to which they agreed 
with each of the items (e.g., "I prefer online social interaction over face-to-face communication"; "I have used Facebook to make myself feel better when I was down"; I have difficulty controlling the amount of time I spend on Facebook"; "I would feel lost if I was unable to access Facebook"; "My Facebook use has created problems for me in my life"). The items were rated on a 8-point scale (from (1) "definitely disagree" to (8) "definitely agree") and they were summed to obtain a continuous variable for PFU. Higher scores on the scale indicate higher levels of PFU. The Cronbach's alpha for the scale was .89 (95\% CI .88-.90). The CFA confirmed an adequate fit between the model and the data: $\chi^{2}(90)=234.75, p<.001 ; \mathrm{CFI}=.97 ; \mathrm{NNFI}=.96$; RMSEA $=.044$, $90 \%$ CI $[.038, .051]$. All the standardized loadings were significant at the $p<.001$ level (mean loading $=.60$ ) thus showing item convergent validity (Anderson \& Gerbin, 1988). For more details see Appendix A.

Personality Traits. Personality traits were assessed using a short form of the Italian version of the Big Five Questionnaire (Caprara et al., 1993; Caprara et al., 1994). It covers five personality traits: agreeableness, conscientiousness, emotional stability, extraversion, and openness. The questionnaire contains 20 items rated on a 5-point scale (from (1) "absolutely false for me" to (5) “absolutely true for me"), so that higher scores indicate higher levels on each trait. The Cronbach's alpha for the scale was $.78(95 \%$ CI $.75-.80)$. The CFA for this sample confirmed the factorial structure of the original validated scale: $\chi^{2}(160)=448.34, p<.001 ;$ CFI $=.95 ;$ NNFI $=.94$; RMSEA $=.047,90 \%$ CI $[.042, .052]$.

Motives. Motives for using Facebook were measured with an adapted version of the Internet Motives Questionnaire (Bischof-Kastner et al. 2014) to Facebook context. Items were translated from English to Italian and back-translated in English by a bilingual psychologist. Simply replacing the word "Internet" with the word "Facebook" made adaptation from Internet to Facebook context. Participants were asked how often they logged on Facebook for different motives, thinking of all the times they have been on Facebook during the last 12 months. The scale includes four motives: coping (e.g. "To forget your worries?"), conformity (e.g. "To be liked by others?"), enhancement 
(e.g. "Because it is exciting?"), and social motive (e.g. "To come into contact with others?"). The questionnaire contains 16 items rated on a 5-point scale (from (1) "never or almost never' to (5) “always or almost always"), so that higher scores indicate higher levels on each motive. The Cronbach's alpha for the scale was .86 (95\% CI .84-.87). The CFA confirmed an adequate fit between the model and the data: $\chi^{2}(90)=224.40, p<.001 ;$ CFI $=.98 ;$ NNFI $=.97 ;$ RMSEA $=.040$, 90\% CI $[.033, .047]$. All the standardized loadings were significant at the $p<.001$ level (mean loading for coping factor $=.79$; mean loading for conformity factor $=.61$; mean loading for enhancement factor $=.59$; mean loading for social factor $=.70$ ) thus showing item convergent validity (Anderson \& Gerbin, 1988). For more details see Appendix B.

Metacognitions. Metacognitions were assessed using the Italian version of the MCQ-30 (Quattropiani, Lenzo, Mucciardi, \& Toffle, 2014). It consists of five factors assessed by six items each: positive beliefs about worry (e.g. "Worrying helps me cope"); negative beliefs about thoughts (e.g. "When I start worrying I cannot stop"); lack of cognitive confidence (e.g. "My memory can mislead me at times"); beliefs about the need to control thoughts (e.g. "Not being able to control my thoughts is a sign of weakness"); and cognitive self-consciousness (e.g. "I pay close attention to the way my mind works"). The questionnaire contains 30 items rated on a 4-point scale (from (1) “definitely disagree" to (2) "definitely agree"). Higher scores indicate higher levels of maladaptive metacognitions. The Cronbach's alpha for the scale was .88 (95\% CI .86-.89). The CFA for this sample confirmed the factorial structure of the original validated scale: $\chi^{2}(395)=2068.12, p<.001$; $\mathrm{CFI}=.92 ; \mathrm{NNFI}=.91 ; \mathrm{RMSEA}=.072,90 \% \mathrm{CI}[.069, .075]$

\subsection{Procedure}

The survey was accessible online from $15^{\text {th }}$ October 2015 to $20^{\text {th }}$ January 2016 . It was promoted by means of a section created in the university institutional website at the Department of Developmental and Social Psychology of the University of XXX (XXX), and an account on Facebook. At the beginning of the survey, participants were asked to provide information about 
their Facebook affiliation (that is, if they have or not a Facebook account), while their demographic information was only requested at the very end of the questionnaire (e.g., age, gender).

\subsection{Data Analyses}

Correlation analyses were conducted in order to test the associations between the variables of interest. The pattern of relationships specified by our theoretical model (Figure 1) was examined through path analysis, using the package Lavaan (Rosseel, 2012) of the software R (R Development Core Team 2012) and utilizing a single observed score for each construct included in the model. In particular, the covariance matrix of the observed variable was analyzed with Maximum Likelihood method estimator and a bootstrap approach (1000 bootstrap samples) was used to calculate bootstrapped confidence intervals to test for mediation. To evaluate the goodness of fit of the model we considered the $\mathrm{R}^{2}$ of each endogenous variable and the total coefficient of determination (TCD; Bollen, 1989; Jöreskog \& Sörbom, 1996). In the tested model, PFU was the dependent variable, personality traits were the independent variables, and motives and metacognitions were the mediators between personality traits and PFU (Figure 1).

\section{Results}

Table 1 shows the means, standard deviations and bivariate correlations between the variables included in the study. As expected, most of the study variables were correlated with each other. In particular, a strong positive correlation was found between PFU and motives, and between PFU and metacognitions, with the exception of cognitive self-consciousness. Moreover, PFU correlated with three personality traits (namely, extraversion, emotional stability, and openness).

A first version of the theoretical model was tested including all the variable of interest. Several path coefficients did not reach the statistical significance and were characterized by a small effect size: the link between four personality traits (emotional stability, openness, agreeableness, and conscientiousness) and PFU, the association between social motive and PFU, the relationship between three metacognitions factors (positive beliefs about worry, need to control thoughts, and cognitive self-consciousness) with PFU; the associations between openness and three motives 
(coping, conformity, and social motive) and three metacognitions (positive beliefs about worry, cognitive confidence, and need to control thoughts); the relationship between extraversion and all motives and three metacognitions (positive beliefs about worry, need to control thoughts, and cognitive self-consciousness); the link between emotional stability with enhancement and social motives, and with cognitive self-consciousness; the associations between agreeableness and three metacognitions (positive beliefs about worry, cognitive confidence, and cognitive selfconsciousness) and three motives (coping, conformity, and enhancement); the relationships between conscientiousness and negative beliefs about thoughts, and three motives (coping, conformity, and enhancement). Therefore, these non-significant links were removed and a second version of the model was evaluated. In this model, all path coefficients were significant at least at the $p<.05$ level. As shown in the Figure (2), the only personality trait directly and negatively predicting PFU was extraversion. Positive, strong and direct associations were found between three motives (coping, conformity, and social) and PFU, and between two metacognitions (negative beliefs about thoughts and cognitive confidence) and PFU. Personality traits are differentially linked to motives to use Facebook (e.g. openness is associated with positive motives; that is enhancement, while extraversion is not associated with motives, and emotional stability seems to have an effect on negative motives, that is coping and conformity).

Along with the direct paths, as shown in Table 2, four indirect relationships were found significant at 5\% level. Specifically, the indirect link between emotional stability and PFU via two motives for using Facebook (coping (-.31) and conformity (-.17)), and via two metacognitions (negative beliefs about thoughts (-.25) and cognitive confidence (-.05)).

The squared multiple correlations for the endogenous variables indicate that the model accounts for $36 \%$ of the variance for the outcome variable (PFU), and $34 \%$ of the variance for one mediator (negative beliefs about thoughts) variable. Lower variance was observed for other mediators (e.g. $8 \%$ for cognitive confidence and $4 \%$ for coping motive). Finally, the total amount variance explained by the model (Total Coefficient of Determination, TCD $=.52$ ) indicated a good 
fit to the observed data. In terms of effect size, TCD $=.52$ corresponds to a correlation of $r=.72$. According to the Cohen's (1988) traditional criteria, this is a very large effect size.

\section{Discussion}

The goal of the present study was to examine the contribution of personality traits, motives and metacognitions to university students' problematic Facebook use (PFU), that is the use of Facebook that may lead to psychological, social, school/or work problems in person's life. Path analysis revealed that three of the four motives for using Facebook (coping, conformity, and enhancement) and two of the five metacognitions (negative beliefs about thoughts and cognitive confidence) predicted PFU. Moreover, only one personality trait (extraversion) appears to be directly, though weakly, linked to PFU, whereas emotional stability indirectly influenced PFU via motives (coping and conformity) and metacognitions (negative beliefs about thoughts and cognitive confidence). These results are consistent with our hypotheses that the relationship between PFU and personality traits would be mediated by motives and metacognitions.

These findings, taken together, suggest that Facebook motives and metacognitions can constitute, to a degree, direct antecedents of PFU, and that personality traits are not directly linked to PFU with the exception for extraversion. The negative link between PFU and extraversion is supported by the social compensation explanation, proposed by Ong and colleagues (Ong, Ang, Ho, Lim, Goh, \& Lee, 2010), and confirmed by previous empirical studies (Kuss \& Griffiths, 2011): the less extraverted individuals are, the more likely they are to use Facebook problematically in order to compensate for their perceived lack of interpersonal and social skills.

With regard to motives for using Facebook, our findings showed that problematic Facebook users seem to use Facebook mainly to cope with low mood, to not feel excluded under the peer pressure to use it, to enhance pleasant feelings, and not to meet social needs or maintain contacts. It can be supposed that using Facebook, for both internal (coping and enhancement) and external (conformity) emotion-regulation motives, is more dysfunctional than social Facebook use, which appears predominantly recreational. The robustness of these findings is highlighted by the 
consistency with results from studies on Internet, alcohol and gambling (Bischof-Kastner et al., 2014). Indeed, as in the case with PIU, alcohol abuse or gambling, Facebook appears a method for regulating emotions, and when such motivation comes into play, Facebook use may escalate into PFU.

With regards to metacognitions, results showed that negative beliefs about thoughts and low cognitive confidence might have an impact on PFU. Why would this be the case? It could be argued that if an individual believes their thinking and emotional states are dangerous and overwhelming (negative beliefs about thoughts) they may be more likely to engage in PFU as a means of cognitive-affective self-regulation. Moreover, it is also possible to argue that low cognitive confidence may lead to perseverative Facebook use in order to control for the presumed accuracy of information remembered helping to reduce temporarily metacognitive dissonance (Spada et al., 2008). Furthermore, it could be speculated that PFU itself is a means to 'actively' worry and ruminate about events and interactions on Facebook (e.g. what friends are doing on Facebook, how they perceive others' profiles, if somebody has 'poked' someone else, etc.).

In addition, motives for using Facebook and metacognitions were found to mediate the relationship between PFU and personality traits. In recent years, the direct role of personality traits in predicting PFU has been widely investigated in Facebook context (Ross, Orr, Sisic, Arseneault, Simmering, \& Orr, 2009; Amichai-Hamburger \& Vinitzky, 2010), showing that low levels of extraversion and emotional stability, in particular, were linked to PFU. The present results add to previous findings by suggesting that these constructs directly influence this maladaptive behaviour and also through motives and metacognitions. Specifically, in this study, emotional stability appeared to be the trait that significantly influences both motives and metacognitions, and, in turn, PFU. In particular, low levels of emotional stability influenced the two motives with negative valence (coping and conformity) which in turn affected PFU: that is, people low on emotional stability may tend to use Facebook to cope with negative mood or to forget problems. Moreover, low levels of emotional stability had an effect on negative beliefs about thoughts concerning 
uncontrollability and danger and cognitive confidence which, in turn, affected PFU: that is, less emotionally stable people may endorse more readily beliefs (in the form of metacognitions) which lead to the employment of maladaptive strategies to control thinking increasing the likelihood of utilizing Facebook to regulate emotional states. Therefore, the data support the potential contribution of metacognitions to PFU, both directly influencing such problematic behaviour and mediating the relationship between personality traits and PFU.

The present results are preliminary and some limitations must be highlighted. First, the sample was not randomly selected and the use of data from a self-report questionnaire may be influenced by recall bias and answer accuracy. Second, the cross-sectional design does not allow definitive statements about causality. Future studies should employ longitudinal designs and examine the specific metacognitive beliefs about Facebook.

Despite these limitations, results of this study have potentially important implications for developing prevention and intervention programmes for young adults. First, since personality traits tend to be quite stable, especially among adults, recent studies have shown the efficacy of evidencebased interventions tailored to other specific individual factors, such as motives and beliefs, to prevent alcohol abuse and to reduce problematic gambling amongst adolescents and young adults (Canale, Vieno, Griffiths, Marino, Chieco, Disperati, Andriolo, \& Santinello, 2016; Disperati, Canale, Vieno, Marino, Chieco, Andriolo, \& Santinello, 2015). Second, there is a large literature demonstrating the effectiveness of metacognitive therapy in treating psychological distress (see Wells, 2013) and growing evidence of its application to addictive behaviours (see Spada, Caselli, Nikčević, \& Wells, 2015). Therefore, developing interventions taking into account of the specific motives and maladaptive metacognitions that lead to PFU might be of value.

In conclusion, the results from the current study provide an important addition to the literature on PFU, suggesting that both Cox and Klinger's motivational model (1988) and Wells' metacognitive model (2000) might be used to develop a theory-driven conceptualization of PFU. 
Such approaches may help further our understanding of motivational and metacognitive factors involved in cause and maintain PFU.

\section{References}

Amichai-Hamburger, Y., \& Vinitzky, G. (2010). Social network use and personality. Computers in Human Behavior, 26, 1289-1295.

Amichai-Hamburger, Y., Wainapel, G., \& Fox, S. (2002). On the Internet no one knows I'm an introvert: Extroversion, neuroticism, and Internet interaction. CyberPsychology and Behavior, 5, 125-128.

Anderson, J.C., \& Gerbing D.W. (1988): Structural Equation Modeling in Practice: A Review and Recommended Two - Step Approach. Psychological Bulletin, 103, 411-423.

Bischof-Kastner, C., Kuntsche, E., \& Wolstein, J. (2014). Identifying Problematic Internet Users: Development and Validation of the Internet Motive Questionnaire for Adolescents (IMQ-A). Journal of Medical Internet Research, 16(10), 230.

Bollen, K. A. (1989). Structural equations with latent variables. New York: Wiley.

Canale, N., Vieno, A., Griffiths, M. D., Marino, C., Chieco, F., Disperati, F., Andriolo, S.,\& Santinello, M. (2016). The efficacy of a web-based gambling intervention program for high school students: A preliminary randomized study. Computers in Human Behavior, 55, 946954.

Canale, N., Vieno, A., Griffiths, M., Rubaltelli, E., \& Santinello, M. (2015). How do impulsivity traits influence problem gambling through gambling motives? The role of perceived gambling risk/benefits. Psychology of Addictive Behaviors, 29(3), 813-823. 
Caplan, S.E. (2010). Theory and measurement of generalized problematic Internet use: A two-step approach. Computers in Human Behavior, 26, 1089-1097.

Caprara, G. V., Barbaranelli, C., \& Livi, S. (1994). Mapping personality dimensions in the big five model. European Journal of Applied Psychology, 44, 9-16.

Caprara, G. V., Barbaranelli, C., Borgogni, L., \& Perugini, M. (1993). The big five questionnaire: A new questionnaire for the measurement of the five factor model. Personality and Individual Differences, 15, 281-288.

Caprara, G.V., \& Cervone, D. (2000). Personality: Determinants, dynamics and potentials. Cambridge: CambridgeUniversity Press.

Cartwright-Hatton, S., \& Wells, A. (1997). Beliefs about worry and intrusions: The meta-cognitions questionnaire and its correlates. Journal of Anxiety Disorders, 11, 279-315.

Chiaburu, D.S., Cho, I., \& Gardner, R. (2015). Authenticity matters more than intelligence and personality in predicting metacognition. Industrial and Commercial Training, 47(7), 363371.

Cohen, J. (1988). Statistical power analysis for behavioral science (2nd ed). Hillsdale, N.J.: Erlbaum.

Cooper, M. L., Agocha, V. B., \& Sheldon, M. S. (2000). A motivational perspective on risky behaviors: The role of personality and affect regulatory processes. Journal of Personality, 68(6), 1059-1088.

Cooper, M.L., Shapiro, C.M., \& Powers, A.M. (1998). Motivations for sex and risky sexual behavior among adolescents and young adults: a functional perspective. Journal of Personality and Social Psychology, 75(6), 1528-1558. 
Cox, W.M., \& Klinger, E. (1988). A motivational model of alcohol use. Journal of Abnormal Psychology, 97(2),168-180.

Disperati, F., Canale, N., Vieno, A., Marino, C., Chieco, F., Andriolo, S., \& Santinello, M. (2015). «Which type of drinker are you?»: an online prevention programme to reduce alcohol consumption and alcohol related problems. Giornale Italiano di Psicologia, 42(1-2), 289302.

Ellison, N. B., Steinfield, C., \& Lampe, C. (2007). The benefits of Facebook “friends:” Social capital and college students' use of online social network sites. Journal of ComputerMediated Communication, 12(4), 1143-1168.

Floros, G., \& Siomos, K. (2013). The relationship between optimal parenting, Internet addiction and motives for social networking in adolescence. Psychiatry Research, 209, 529-534.

Hughes, D. J., Rowe, M., Batey, M., \& Lee, A. (2012). A tale of two sites: Twitter vs. Facebook and the personality predictors of social media usage. Computers in Human Behavior, 28(2), 561-569.

Joinson, A. N. (2008, April). Looking at, looking up or keeping up with people?: motives and use of facebook. In Proceedings of the SIGCHI conference on Human Factors in Computing Systems (pp. 1027-1036). ACM, Florence, Italy.

Jöreskog, K.G., \& Sörbom, D. (1996). LISREL 8: User's reference guide. Chicago: Scientific Software International.

Kirschner, P.A., \& Karpinski, A.C. (2010). Facebook and academic performance. Computers in Human Behavior, 26, 1237-1245. 
Kuntsche, E., Le Mével, L., \& Berson I. Development and Validation of the Motives for Listening to Music Questionnaire (MLMQ). Psychology of Music.

Kuss, D. J., \& Griffiths, M. D. (2011). Addiction to social networks on the Internet: A literature review of empirical research. International Journal of Environment and Public Health, 8, $3528-3552$.

Lee, Z.W.Y., Cheung, C.M.K., \& Thadani, D.R. (2012). An Investigation into the Problematic Use of Facebook, 45th Hawaii International Conference on System Sciences.

Lenzi, M., Vieno, A., Altoè, G., Scacchi, L., Perkins, D.D., Zukauskiene, R., \& Santinello, M. (2015). Can Facebook Informational Use Foster Adolescent Civic Engagement? American Journal of Community Psychology, 55, 444-454.

Marshall, T. C., Lefringhausen, K., \& Ferenczi, N. (2015). The Big Five, self-esteem, and narcissism as predictors of the topics people write about in Facebook status updates. Personality and Individual Differences, 85, 35-40.

Mazzardis, S., Vieno, A., Kuntsche, E., \& Santinello, M. (2010). Italian validation of the drinking motives questionnaire revised short form (DMQ-R SF). Addictive Behaviors, 35(10), 905908.

McCrae, R.R., \& John, O.P. (1992). An introduction to the five-factor model and its applications. Journal of Personality, 60(2), 175-215.

Moreau, A., Laconi, S., Delfour, M., \& Chabrol, H. (2015). Psychopathological profiles of adolescent and young adult problematic Facebook users. Computers in Human Behavior, 44, 64-69. 
Muise, A., Christofides, E., \& Desmarais, S. (2009). More information than you ever wanted: Does Facebook bring out the green-eyed monster of jealousy? CyberPsychology \& Behavior, 12, 441-444.

Ong, E.Y.L., Ang, R.P., Ho, J.C.M., Lim, J.C.Y., Goh, D.H., \& Lee, C.S. (2010). Narcissism, extraversion and adolescents' self-presentation on Facebook. Personality and Individual Differences, 50, 180-185.

Papacharissi, Z. \& Mendelson, A. (2011). Toward a new(er) sociability: Uses, gratifications and social capital on Facebook. In S. Papathanassopoulos (Ed.), Media perspectives for the 21st century (pp. 212-230). Oxon, UK: Routledge.

Quattropiani, M.C., Lenzo, V., Mucciardi, M., \& Toffle, M.E. (2014). Psychometric properties of the Italian version of the Short Form of the Metacognitions Questionnaire (MCQ-30). Bollettino di Psicologia Applicata, 269, 29-41.

R Core Team (2013). R: A language and environment for statistical computing [Computer software manual]. Vienna, Austria Available from http://www.R-project.org/.

Ross, C., Orr, E.S., Sisic, M., Arseneault, J.M., Simmering, M.G., \& Orr, R.R. (2009). Personality and motivations associated with Facebook use. Computers in Human Behavior, 25, 578 586.

Rosseel, Y. (2012). Lavaan: An R package for structural equation modeling. Journal of Statistical Software, 48, 1-36.

Ryan, T., Chester, A., Reece, J., \& Xenos, S. (2014). The uses and abuses of Facebook: A review of Facebook addiction. Journal of Behavioral Addictions, 3, 133-148. 
Sheldon, P. (2008). Student favorite: Facebook and motives for its use. Southwestern Mass Communication Journal, 23(2), 39-53.

Spada, M.M., Caselli, G., Nikčević, A.V., \& Wells, A. (2015). Metacognition in addictive behaviours. Addictive Behaviors, 44, 9-15.

Spada, M.M., Langston, B., Nikčević, A.V., \& Moneta, G. B. (2008). The role of metacognitions in problematic Internet use. Computers in Human Behavior, 24(5), 2325-2335.

Wells, A. (2000). Emotional Disorders and Metacognition: Innovative Cognitive Therapy. Wiley: Chichester.

Wells, A. (2013). Advances in Metacognitive Therapy. International Journal of Cognitive Therapy, $6,186-201$.

Wells, A., \& Cartwright-Hatton, S. (2004). A short form of the metacognitions questionnaire: properties of the MCQ-30. Behaviour Research and Therapy, 42(4), 385-396.

Young, K. (1999). Internet addiction: Evaluation and treatment. Student British Medical Journal, 7 , $351-352$ 
Appendix A. Standardized factor loadings for the Problematic Facebook Use Scale (response format = from (1) "definitely disagree" to (8) "definitely agree").

\begin{tabular}{lll}
\hline Items & Loadings & SE \\
\hline 1. I have used Facebook to talk with others when I was feeling isolated & .491 & .038 \\
2. I would fell lost if I was unable to go on Facebook & .659 & .041 \\
3. I have difficulty controlling the amount of time I spend on Facebook & .675 & .045 \\
4. I prefer online social interaction over face-to-face communication & .384 & .037 \\
5. My Facebook use has made it difficult for me to manage my life & .638 & .032 \\
6. I have used Facebook to make myself feeling better when I was down & .660 & .040 \\
7. When offline, I have a hard time trying to resist the urge to go on & .727 & .043 \\
Facebook & & .573 \\
8. My Facebook use has created problems for me in my life & .033 \\
9. I find it difficult to control my Facebook use & .687 & .043 \\
10. Online social interaction is more comfortable for me than face-to-face & .472 & .036 \\
interaction & & \\
11. I have used Facebook to make myself feel better when I've felt upset & .669 & .039 \\
12. When I haven't been on Facebook for some time, I become preoccupied & .767 & .039 \\
with the thought of going on Facebook & & \\
13. I have missed social engagements or activities because of my Facebook & .540 & .029 \\
use & & \\
14. I think obsessively about going on Facebook when I am offline & .646 & .032 \\
15. I prefer communicating with people online rather than face-to-face & .456 & .033 \\
\hline
\end{tabular}


Appendix B. Standardized factor loadings for the Facebook Motives Questionnaire (response format $=$ from (1) "never or almost never" to (5) "always or almost always").

\begin{tabular}{lll}
\hline Items, motives & Loadings & SE \\
\hline How often do you go on Facebook: & & \\
Coping & .722 & .028 \\
To forget your worries? & .817 & .027 \\
Because it helps you when you feel depressed or irritated? & .849 & .030 \\
To cheer yourself up when you are in a bad mood? & .764 & .028 \\
To forget about your problems? & & \\
Conformity & .353 & .019 \\
Because your friends pressurized you to do it? & .691 & .028 \\
Because you would like to belong to a certain circle of friends? & .721 & .031 \\
To be liked by others? & .665 & .032 \\
To not feel excluded? & & \\
Enhancement & .801 & .030 \\
Because it gives you a pleasant feeling? & .651 & .021 \\
Because it is exciting? & .519 & .017 \\
To experience a feeling of exaltation? & .404 & .025 \\
Simply because it is fun? & & \\
Social & .488 & .026 \\
To come into contact with others? & .807 & .031 \\
Because it is fun to be in contact with others? & .799 & .032 \\
To improve your contact with friends and acquaintances? & .712 & .031 \\
To share a special occasion with friends? & & \\
\hline
\end{tabular}


Figure 1: The theoretical model of Problematic Facebook Use developed for testing in the study.

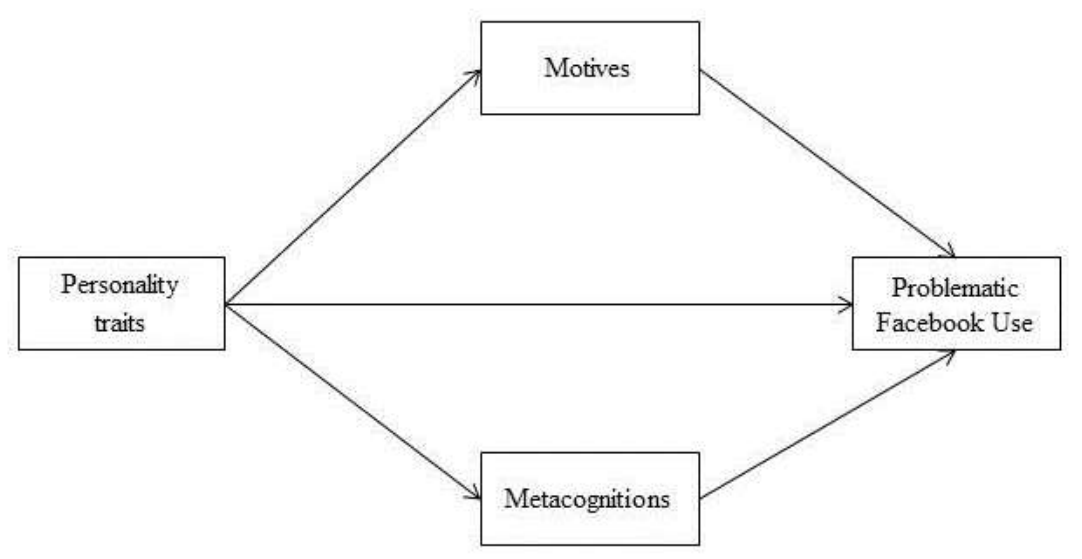


Figure 2: The final model of Problematic Facebook Use, showing the interrelationships between the variables.

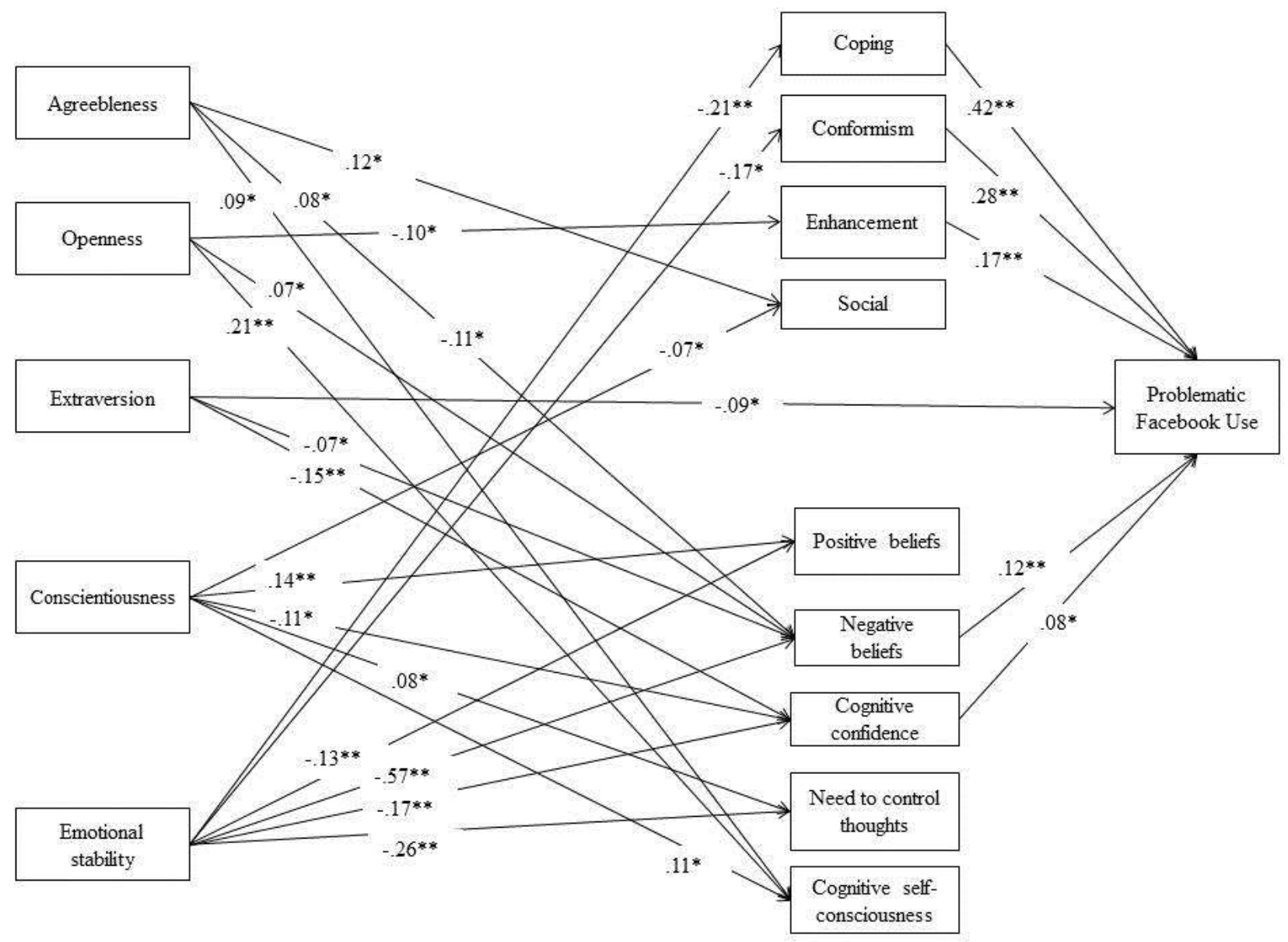

Notes: ${ }^{*} p<0.05,{ }^{* *} p<0.01 ; \mathrm{N}=815$. 
Table 1: Correlation matrix for the study variables.

\begin{tabular}{|c|c|c|c|c|c|c|c|c|c|c|c|c|c|c|c|c|}
\hline & $\mathrm{M}$ & SD & 1 & 2 & 3 & 4 & 5 & 6 & 7 & 8 & 9 & 10 & 11 & 12 & 13 & 14 \\
\hline $\begin{array}{l}\text { 1. Problematic Facebook } \\
\text { Use }\end{array}$ & 28.74 & 14.12 & 1 & & & & & & & & & & & & & \\
\hline 2. Emotional stability ${ }^{\mathrm{a}}$ & 11.92 & 3.46 & $-.22 * *$ & 1 & & & & & & & & & & & & \\
\hline 3. Extraversion ${ }^{\mathrm{a}}$ & 15.29 & 2.78 & $-.18 * *$ & $.24^{*}$ & 1 & & & & & & & & & & & \\
\hline 4. Conscientiousness ${ }^{a}$ & 13.82 & 3.50 & .01 & .05 & $.27 * *$ & 1 & & & & & & & & & & \\
\hline 5. Agreeableness ${ }^{\mathrm{a}}$ & 16.33 & 2.48 & -.06 & $.09 * *$ & $.37 * *$ & $.18^{* *}$ & 1 & & & & & & & & & \\
\hline 6. Openness ${ }^{\mathrm{a}}$ & 15.37 & 2.72 & $-.07 *$ & $.11 * *$ & $.25^{* *}$ & .06 & $.23^{* *}$ & 1 & & & & & & & & \\
\hline 7. Coping ${ }^{b}$ & 6.11 & 2.86 & $.63 * *$ & $-.21 * *$ & $-.10^{* *}$ & .02 & -.02 & $-.09 *$ & 1 & & & & & & & \\
\hline 8. Conformity ${ }^{b}$ & 5.58 & 2.19 & $.56^{* *}$ & $-.17 * *$ & $-.12 * *$ & -.02 & -.07 & -.07 & $.49 * *$ & 1 & & & & & & \\
\hline 9. Enhancement ${ }^{\mathrm{b}}$ & 6.88 & 2.44 & $-50 * *$ & $-.08 *$ & -.06 & -.05 & -.06 & $-.10^{* *}$ & $.53 * *$ & $.45^{* *}$ & 1 & & & & & \\
\hline 10. Social ${ }^{\mathrm{b}}$ & 9.91 & 3.68 & $.29 * *$ & -.05 & .06 & -.05 & $.11 * *$ & $.08^{*}$ & $.25^{* *}$ & $.36^{* *}$ & $.44 * *$ & 1 & & & & \\
\hline 11. Positive beliefs ${ }^{c}$ & 12.40 & 4.21 & $.21 * *$ & $-.13 * *$ & .06 & $.14^{* *}$ & .07 & .02 & $.15^{* *}$ & $.18^{* *}$ & $.16^{* *}$ & $.12 * *$ & 1 & & & \\
\hline 12. Negative beliefs ${ }^{c}$ & 12.84 & 4.65 & $.34 * *$ & $-.57 * *$ & $-.16^{* *}$ & -.01 & .02 & .01 & $.26^{* *}$ & $.30 * *$ & $.12 * *$ & $.11 * *$ & $.26^{* *}$ & 1 & & \\
\hline 13. Cognitive confidence ${ }^{c}$ & 11.51 & 4.32 & $.27 * *$ & $-.21 * *$ & $-.22 * *$ & $-.16^{* *}$ & -.05 & -.06 & $.19 * *$ & $.22 * *$ & $.11 * *$ & .07 & $.22 * *$ & $.33 * *$ & 1 & \\
\hline 14. Need control thoughts ${ }^{c}$ & 12.17 & 3.38 & $.26 * *$ & $-.25 * *$ & $-.09 *$ & $.07 *$ & -.02 & -.02 & $.20 * *$ & $.25^{* *}$ & $.14^{* * *}$ & $.09 *$ & $.32 * *$ & $.54 * *$ & $-31 * *$ & 1 \\
\hline $\begin{array}{l}\text { 15. Cognitive self- } \\
\text { consciousness }\end{array}$ & 16.65 & 3.45 & .04 & .03 & $.15^{* *}$ & $.14 * *$ & $.16^{* *}$ & $.24 * *$ & .03 & .04 & .01 & $.11 * *$ & $-24 * *$ & $.18 * *$ & -.01 & $.33 * *$ \\
\hline
\end{tabular}

Notes: ${ }^{*} p<0.05,{ }^{* *} p<0.01 ; \mathrm{N}=815 .{ }^{\mathrm{a}}=$ Personality traits; ${ }^{\mathrm{b}}=$ Motives $;{ }^{\mathrm{c}}=$ Metacognitions. 
Table 2: Standardized bootstrapped estimates of the indirect effects (with $95 \%$ confidence intervals) of independents (personality traits) on the dependent (PFU) through the proposed mediators (motives for using Facebook and metacognitions) linked to the dependent.

\begin{tabular}{|c|c|c|c|c|}
\hline \multirow[t]{2}{*}{ Independent variables } & \multirow[t]{2}{*}{ Mediators } & \multirow{2}{*}{$\begin{array}{c}\text { Dependent } \\
\text { (PFU) }\end{array}$} & \multicolumn{2}{|c|}{ Confidence intervals } \\
\hline & & & Lower bound & $\begin{array}{l}\text { Upper } \\
\text { bound }\end{array}$ \\
\hline \multicolumn{5}{|l|}{ Emotional stability $^{\mathrm{a}}$} \\
\hline & $\begin{array}{l}\text { Coping } \\
\text { Conformity }\end{array}$ & $\begin{array}{l}-.51 \\
-.17\end{array}$ & $\begin{array}{l}-.45 \\
-.27\end{array}$ & $\begin{array}{l}-.17 \\
-.06\end{array}$ \\
\hline & Negative beliefs ${ }^{\mathrm{c}}$ & -.25 & -.37 & -.12 \\
\hline & Cognitive confidence $^{\mathrm{c}}$ & -.05 & -.09 & -.00 \\
\hline \multicolumn{5}{|l|}{ Extraversion $^{\mathrm{a}}$} \\
\hline & Negative beliefs ${ }^{\mathrm{c}}$ & -.04 & -.08 & .00 \\
\hline & Cognitive confidence $^{\mathrm{c}}$ & -.05 & -.10 & .00 \\
\hline \multicolumn{5}{|l|}{ Openness $^{\mathrm{a}}$} \\
\hline & Enhancement $^{\mathrm{b}}$ & -.08 & -.16 & -.00 \\
\hline & Negative beliefs ${ }^{\mathrm{c}}$ & -04 & -.00 & .08 \\
\hline \multicolumn{5}{|l|}{ Agreeableness $^{\mathrm{a}}$} \\
\hline \multirow{2}{*}{ Conscientiousness $^{\mathrm{a}}$} & Negative beliefs ${ }^{\mathrm{c}}$ & .05 & -.00 & .10 \\
\hline & Cognitive confidence $^{\mathrm{c}}$ & -.03 & -.07 & .00 \\
\hline
\end{tabular}

Note: ${ }^{\mathrm{a}}=$ Personality traits $;{ }^{\mathrm{b}}=$ Motives $;{ }^{\mathrm{c}}=$ Metacognitions. 